\title{
La idea de juventud en Chile en el siglo XX Aproximación genealógica al discurso de las revistas de juventud ${ }^{*}$
}

\author{
Óscar Aguilera Ruiz \\ Recibido: Enero 15 - Aprobado: Marzo 15
}

\begin{abstract}
Resumen
El texto expone resultados preliminares de una investigación sobre la construcción histórica de la idea de juventud en las revistas chilenas en el periodo 1900-1940. Para ello, el artículo presenta el contexto comunicacional de las revistas de juventud, las identidades juveniles reconocibles en las primeras décadas del siglo XX y los regímenes de juvenilidad que se comienzan a perfilar. Concluimos de manera provisional algunas cuestiones vinculadas con el proceso de estabilidad semiótica de la idea de juventud y el papel que las imágenes, específicamente las publicitarias, cumplen en la construcción de lo juvenil.
\end{abstract}

Palabras clave: Juventud, identidades, revistas juveniles, genealogía, discurso

* Este manuscrito se enmarca en el desarrollo del Proyecto Fondecyt 11110373 "Genealogía de lo juvenil en Chile en el Siglo XX. Emergencias identitarias y políticas de visibilidad c.1906-c.1986, del cual el autor es investigador responsable. Agradezco el importante diálogo y reflexión con la antropóloga Marcela Saa en el desarrollo del trabajo investigativo que hace posible este artículo.

** Doctor en Antropología Social i Cultural. Académico en Universidad Católica del Maule, responsable de proyecto FONDECYT «Genealogía de lo Juvenil» No 11110373. Dirección electrónica: oaguilera@ucm.cl 


\title{
The Idea of Youth in Chile during the $20^{\text {th }}$ Century. A Genealogical Approach to the Speech of Juvenile Magazines.
}

\begin{abstract}
This article exhibits preliminary results of a research about the historical construction of the idea of youth given in Chilean magazines between 1900 and 1940. For this purpose, the article shows the communicational context of juvenile magazines, juvenile identities with high recognition during the first decades of the 20th century and the juvenility regimes that were arising at that time. Temporary conclusions were given about some topics related to the semiotic stability process of the idea of youth and the role that images (specifically advertising images) play to construct what is juvenile.
\end{abstract}

Key words: Youth; identities; juvenile journals; genealogy; speech. 


\section{Introducción}

La preocupación por la juventud tiene una antigua existencia y una considerable producción teórica y empírica. En las primeras décadas del siglo XX en EE. UU. se desarrolla a partir de los estudios urbanos inscritos en la Escuela de Chicago (Whyte 1971), en el trabajo de la antropología cultural (Mead 1985), o en el propio desarrollo de la psicología (Hall 1915). Otro tanto ocurre en Europa, ya sea en los enfoques filosóficos (Ortega y Gasset 1955) o en las perspectivas sociohistóricas (Manheimm1993), así como en los estudios culturales británicos que interrogan la relación entre medios de comunicación, industria de la cultura e identidades juveniles (Hall E Jefferson 2010, Savage 2009). De modo similar, en América Latina reconocemos una tradición ensayística que en diversas latitudes se hizo cargo del análisis de la existencia social de un sujeto definido por su condición juvenil (Rodó 1961, Vasconcelos 1966) y que se extiende hasta nuestros días con los aportes del campo de la comunicación (Barbero 2002, Muñoz 2006) y de la antropología (Reguillo 2000).

Por otra parte, y a partir de los estados del arte en la materia, reconocemos que la idea de juventud se ha asumido más como un punto de partida (existe) antes que como un punto de llegada del cual dar cuenta (cómo se ha producido). Al respecto, podemos sostener, además, que no existe una lectura en clave histórica del papel de las producciones culturales, y particularmente la prensa, en la configuración de la idea de juventud en Chile y en América Latina. Esta situación es de vital importancia, si asumimos los presupuestos de Feixa (2008) en cuanto a que la sociedad, vía industrias de la cultura, elabora y oferta un repertorio de imágenes culturales (atributos ideológicos y simbólicos) de lo que es la juventud y con las cuales los sujetos dialogan, negocian, y elaboran sus propias identidades. Esta idea también se encuentra en Savage (2009) quien a partir de un minucioso análisis de las noticias de periódicos europeos reconstruye el proceso de creación del concepto de juventud y que a su juicio revoluciona el siglo XX.

El análisis crítico del conocimiento sobre juventud tanto en Colombia (Escobar, 2004) como en Argentina (Chaves, 2006) nos permite sostener un doble vacío en la producción de conocimiento sobre juventud, diagnóstico que hacemos extensivo a Chile: la escasez de estudios con perspectiva histórica sobre juventud, y un insuficiente tratamiento de la relación comunicación, medios y jóvenes, que en la mayoría de los casos presentan una lectura desde la alienación y la criminalización.

De allí que preguntarnos por el modo en que esta idea/categoría ha sido producida en el contexto chileno a través de revistas de juventud sea el propósito del presente artículo. Específicamente, quisiéramos proponer y someter a debate una aproximación que señala a la juventud como una idea/atributo en cuya trayectoria han tenido existencia diversas emergencias identitarias, inscritas en regímenes de juvenilidad específicos y con diversos resultados en términos de subjetividad y gobierno de las mismas. Investigar la juventud, desde una perspectiva como la anteriormente enunciada, supone desplegar una mirada de largo plazo que permita dar cuenta de las trayectorias que ha seguido la construcción sociocultural de la juventud. 
Para lograr el propósito antes mencionado, rastrear el modo en que emerge y se desarrolla la idea de juventud en las revistas de juventud chilenas en el siglo XX, nos proponemos, en primer lugar, situar desde el campo de los estudios en comunicación la pregunta por la juventud; en segundo lugar, construir una perspectiva teórica que aquí hemos denominado genealogía de lo juvenil y que enfatiza en el doble registro semiótico que produce juventud, tanto como representación y significado, como aquello que se inscribe más bien en el campo del deseo y los imaginarios antes incluso que ellos puedan ser significados; en tercer lugar, exponemos los resultados parciales del proceso investigativo, fundamentalmente lo referido al contexto comunicacional de revistas de juventud, las emergencias identitarias reconocibles en las primeras décadas del siglo XX y los regímenes de juvenilidad que se comienzan a perfilar. Finalmente, concluimos de manera provisional algunas cuestiones vinculadas con el proceso de estabilización semiótica de la idea de juventud, y el papel que las imágenes, y específicamente las publicitarias, cumplen en la construcción de lo juvenil.

\section{1.- Medios de comunicación y regímenes de juvenilidad}

Un apunte inicial sobre la relación juventud y comunicación puede ser útil para situar nuestro propósito: es necesario distinguir entre comunicación sobre y comunicación desde lo juvenil. Es decir, la comunicación planteada y construida desde el mundo adulto, y aquella otra que elaboran los jóvenes y que interpela al mundo adulto. Pero sea cual fuere la entrada a este campo investigativo, no es menor considerar que la relación comunicativa se despliega en un contexto marcadamente adultocéntrico, y por lo tanto, desigual y estratificado entre adultos y jóvenes.

En dicho marco comunicacional se despliegan formas de nombrar, se asignan atributos socioculturales, y se determinan roles sociales a los jóvenes. Por ello, preguntarnos por la juventud supone de entrada la puesta en marcha de una política de la cultura que exige visibilizar los modos desiguales de distribución y asignación de atributos socioculturales. En ese sentido, la escena mediática se convierte en un analizador central de las luchas por la constitución de las visibilidades, en una doble dimensión hegemónica y contra hegemónica. Para Gramsci (1975) la hegemonía remite al proceso mediante el cual en un orden social estratificado aquellos que detentan el poder (económico, político, cultural) logran imponer como "naturales" sus propios valores y significados ante los grupos subordinados.

Parece sensato señalar desde estas posturas que una discusión de perspectiva histórica respecto al papel que la prensa tendría en la constitución de estas visibilidades se vuelve una tarea estratégica. Sobre este campo investigativo en Chile existen autores que analizan la constitución del sistema de medios y que toman como punto de partida el inicio de la prensa moderna a fines del siglo XIX y comienzos del siglo XX (Ossandón, 2002; Santa Cruz, 1999). Mención especial merece el trabajo conjunto de Ossandón y Santa Cruz (2001) en el que se construye un marco histórico de comprensión del papel de la prensa en los procesos de modernización de la sociedad chilena en el siglo XX, proponiendo de esta forma un estudio sistemático no solo de lo que se dice (tratar a los 
medios y la prensa solo como fuente) sino también el cómo se dice o enuncia el contenido y con qué finalidades comunicativas, lo que convierte el discurso de la prensa en un objeto de estudio en sí mismo. Si bien los medios de comunicación han sido construidos como objetos de estudio para el campo disciplinario, se observa un carácter más bien descriptivo (Hurtado, 1989) y de corte sincrónico y contingente (Ossa, 1998). En síntesis, son pertinentes las observaciones críticas de Bernedo sobre los estudios en comunicación desarrollados en Chile (2004) respecto a la débil conceptualización y profundidad de los mismos, hasta ahora desarrollados en este campo.

Es así como este proceso de producción de la idea de juventud y la constitución de identidades juveniles, y que aquí denominamos políticas de visibilidad, se ubica en el centro de los conflictos y las querellas en la Contemporaneidad. Asimismo, ubica a las identidades juveniles hegemónicas en una vía de acceso privilegiado para observar los mecanismos productores de juventud, en tanto el observar las tensiones, contradicciones y negociaciones discursivas respecto a quiénes son "los jóvenes" nos permitirá una aproximación tanto a quienes obtienen el reconocimiento identitario como a los que quedan al margen. A ello se apunta con la noción de emergencias identitarias. Señalamos, además, que la construcción de las identidades opera a través de un sistema de diferencias; por lo tanto, determinar los límites de lo que es reconocido como "juventud" nos abre la puerta para acceder precisamente a aquellos que lo disputan, niegan o subvierten. A ello nos referimos en este proyecto como regímenes de juvenilidad. De esa manera reconstruimos no solo los atributos a ella asignadas sino los modos de producción involucrados.

Lo anterior supone elaborar un punto de partida respecto a la emergencia y reconocimiento de los jóvenes como actores sociales diferenciado, y parece pertinente ubicar más claramente ese punto a inicios del siglo XX. Al respecto, es significativo el esfuerzo realizado en el campo investigativo de la niñez que señala que durante el siglo XIX se va produciendo paulatinamente un proceso de diferenciación en el paso a la adultez, ya no de manera directa como en el siglo XVIII sino a través de una categoría social intermedia que permite delimitar los comienzos y finales de las edades: en el último caso, sitúan la finalización de la niñez en el momento en que los niños cuentan con un espacio institucionalizado en el cual continuar el proceso de aprendizaje iniciado en su casa (Rojas, 2009). Esta postura es complementaría con la propuesta de Toro (2012) quien para rastrear la definición del sujeto juvenil se aproxima a los discursos públicos de los textos escolares y de la prensa de la época en que se institucionaliza la enseñanza secundaria, y se crean los liceos, esto es, a partir de 1879.

En síntesis, la preocupación por las modalidades comunicativas que desarrolla la prensa en su acompañamiento a la construcción del sujeto juvenil, a través de los regímenes de juvenilidad y las emergencias identitarias visiblizadas, permite acceder de manera privilegiada a las formas de relación intercultural entre el mundo adulto y el mundo joven, pero también entre los propios jóvenes. Esta comprensión permite ampliar el propio campo de estudios de la comunicación intercultural (Rodrigo 1999), que hasta ahora no ha considerado de modo sistemático el análisis específico de los modos culturales de 
relación social entre las edades, modos que son propuestos a través de los medios y las diversas producciones culturales.

\section{2.- Juventud en perspectiva genealógica}

Desde el campo investigativo sobre lo juvenil se ha venido insistiendo en los últimos años en la importancia de perspectivas en clave histórica que permitan analizar relacionalmente la condiciones de existencia social de juventud (Pérez-Islas y Urteaga 2004: Savage 2009, Gonzalez y Feixa 2012). La complejidad de la tarea supone el reconocimiento de dimensiones materiales y simbólicas, el papel de la agencia juvenil, a la vez que el peso de la estructura social, la búsqueda de la autonomía y su tensión con la subordinación al mundo adulto. Todo lo cual nos lleva a concordar con S. Morch cuando señala que "(...) el secreto de la juventud se encuentra fuera de ella, es decir, en los cambios de la sociedad". (1993:21). En dicha dirección, se encuentra la propuesta de Urteaga (2004) de rastrear las imágenes juveniles (en un sentido visual, pero también de cómo se narra la juventud), proponiendo para ello dos entradas analíticas: la construcción cultural de la juventud, y la construcción juvenil de la cultura. Si bien no profundiza mayormente en dichos abordajes, parece sugerente para los fines de nuestra investigación reubicar la discusión teórica de manera explícita en la construcción cultural de la juventud a partir de los medios de comunicación.

La recuperación de claves relacionales como las enunciadas previamente se complementa con otro eje de lectura que ubica la pregunta por la juventud en el marco de una interacción autodescriptiva/heterodescriptiva, inscrita en la estratificación por edad de la sociedad y que, por lo tanto, refiere a la distinción etaria, así como a la composición societal que le asigna un lugar precisamente a la edad como modo de gestión y control de lo social y que va sedimentando sentidos en su transcurrir histórico. De allí que la invocación a una perspectiva histórica supone el despliegue de una analítica que politice la historia, en tanto los significados asociados a la edad se vuelven un capital político que restringe o promueve la emancipación: basta pensar, como señala Touraine (1997) en las imágenes de la juventud como amenaza o como promesa, que de tanto en tanto "se usan para movilizar el mismo tipo de marcos temporales en las negociaciones sobre qué tipos de poder están disponibles, dónde se pueden ejercitar, y por quién" (Durham, 2000: 118).

De lo anterior se deriva que para entender la juventud, su producción como idea y su estabilización como signo en la sociedad chilena durante el siglo XX, hemos de recurir a una perspectiva genealógica. Esto supone hacerse cargo de dos desplazamientos conceptuales importantes en el análisis histórico: del origen a las procedencias, y de la representación a los dispositivos. Ambos movimientos teóricos discuten la idea de historia como una secuencia articulada y coherente de sujetos, así como la naturalidad de los atributos y características asociados a los sujetos y los hechos indagados.

Señala Foucault que toda genealogía "se opone al origen" en tanto no comparte las significaciones metahistóricas o teleológicas que no son sino modalidades ideales de historia que fundan una verdad "(...), especie de error, que tiene para sí el no poder ser 
refutada, sin duda, porque la larga cocción de la historia la ha vuelto inalterable" (2008: 22). Y qué, si no eso, hay detrás de las actas de nacimiento de la juventud, que la ubican en la Revolución Industrial o en la expansión de la posguerra, cuando no en la llegada del rock and roll y su traducción nacional de la nueva ola en Chile (González 2010). Más bien, será tarea genealógica encontrar las singularidades que en su trayectoria han permitido una determinada forma social, y por ello recurre a la procedencia como principio histórico que (...) permite disociar el Yo y hacer pulular, en los lugares y posiciones de su síntesis vacía, mil acontecimientos ahora perdidos" (Foucault, 2008: 26), lo que pone al cuerpo en el centro del análisis en tanto en él se inscriben los acontecimientos, a él lo visten con determinados ropajes, lo ubican en determinados lugares, consume determinados productos y lo asocian con singulares mercancías. De allí la efebolatría clásica del cuerpo terso y vigoroso del mundo helénico, la displicencia de James Dean con el cigarrillo en los labios exhibiendo rebeldía, o los humores que recorren el Balance Patriótico de Huidobro en 1925 cuando exclama:

Un país que apenas a los cien años de vida está viejo y carcomido, lleno de tumores y de supuraciones de cáncer como un pueblo que hubiera vivido dos mil años y se hubiera desangrado en heroísmos y conquistas (...) Que se vayan los viejos y que venga juventud limpia y fuerte, con los ojos iluminados de entusiasmo y de esperanza.

Por otra parte, la focalización excesiva en las representaciones de juventud invisibiliza los dispositivos que las producen. De allí que se vuelva imprescindible problematizar el modo semiótico de análisis de los significados producidos. Uno es el plano de la representación y la significación que, a través del lenguaje, permite comprender la producción de un sujeto, de una identidad, o de un individuo y la correspondiente asignación de roles y funciones. Dicha operación modula, o intenta hacerlo, los significados elaborados por/ desde el cuerpo que no se inscribe necesariamente en ese plano "racionalizante" del lenguaje y la comunicación, abriendo así una vía de crítica al modelo semiótico convencional. Por lo tanto, se obliga a la pregunta por aquel plano/registro de producción de significados que se orienta directamente al gobierno del cuerpo a través de "semióticas asignificantes" que (...) en lugar de producir una significación, desencadenan una acción, una reacción, un comportamiento, una actitud, una postura" (Lazaratto 2006). Y en el que la prensa, las imágenes y el consumo, juegan un papel fundamental a la hora de indagar en la producción de subjetividad, la juvenil en este caso.

En síntesis, se requiere una analítica de la gubernamentalidad que permita comprender precisamente el modo en que desde antes de representar a la juventud ya había sido puesta en marcha una semiótica que desea, acciona y produce juventud, independiente de lo que ella represente o pueda llegar a significar. Aquí la noción de gobierno refiere a la conducción de la conducta, a una forma de actividad práctica que tiene el propósito de conformar, guiar o afectar la conducta de uno mismo y/o de otras personas (De Marinis, 1999). Foucault (1991) utiliza el concepto de gobierno en un sentido amplio, fuertemente vinculado con su antiguo significado y resaltando la cercanía entre relaciones de poder y los procesos de subjetivación. Al respecto, Castro Gómez (2009) profundiza en la importancia que tales componentes imaginarios anteriores a la representación y la significación tienen 
en las personas a la hora de generar identificaciones con unas determinadas formas de vida, unos valores e identidades que no siempre tienen/descansan en unas condiciones materiales o que simplemente todavía "no son" como es el que caso precisamente de la idea de juventud en las primeras décadas del siglo XX.

\section{Metodología}

Señalamos previamente que una de las debilidades manifiestas en los estudios sobre juventud es la escasa atención prestada al campo de las producciones culturales como fuente de interrogación y análisis. De allí que se plantee una estrategia documental de carácter cualitativo que permita dar cuenta del proceso histórico cultural que se aborda como problema investigativo. Los usos de los documentos y su relevancia están ampliamente documentados en las ciencias sociales y humanas (Valles 1999, Feixa 2008, entre otros).

Para el análisis hemos desplegado una aproximación genealógica fundamentada en una comprensión crítica del discurso, con el propósito de generar unidades de sentido y regímenes de discurso antes que secuencias semánticas aisladas de su contexto de producción y enunciación. Al respecto señala Foucault que los discursos en tanto prácticas discontinuas presentan discontinuidades, irrupciones impensadas, condiciones de posibilidad histórica (2008). De allí entonces que el discurso, en tanto vector de ideas, representación e ideologías, opera de forma situada, tal como lo sostiene Angenot (2010):

Una idea siempre es histórica: no se puede tener cualquier ideas, creencia u opinión, mantener cualquier "programa de verdad" en cualquier época y en cualquier cultura. En cada época, la oferta se limita a un conjunto restringido, con predominancias, conflictos y emergencias (p. 16).

A partir de la hemeroteca de la Biblioteca Nacional de Chile, se rastrearon un total de 115 revistas que cumplen estos criterios, y fueron trabajadas un total de 84. De ellas fueron seleccionados un total de 947 documentos que constituyen el material desde el cual se presentan estos resultados preliminares. El periodo abarcado va desde 1906 a 1986, y se utilizó un doble criterio de selección y delimitación de la unidad de análisis: la adscripción organizacional de las publicaciones y el concepto de acontecimiento como recurso metodológico y técnico:

1. Adscripción organizacional. A partir de una exploración inicial a la base de datos de publicaciones periódicas (diarios y revistas) del catálogo de la Biblioteca Nacional, encontramos un conjunto de publicaciones que siguiendo un criterio de adscripción organizacional (construido ad hoc para este proyecto) nos permite generar una primera delimitación del total de publicaciones del periodo: adscripción religiosa (La Voz de la Y-1950, Sursum-1929, entre otras), adscripción política (Espartaco-1959, Bandera Negra-1947, entre otras) , adscripción asociativa (Juventud-1947, Juventud-1918), adscripción mediática (Ritmo de la Juventud-1965, Lectura para la juventud-1939, entre otras). Se trata, por tanto, de una opción metodológica conocida como muestreo intencionado. 
2. Acontecimiento. De Certau (1995) define al acontecimiento como una revolución simbólica que implica una transformación de lugares, una redefinición de los códigos sociales, una impugnación de las relaciones sociales y la creación de símbolos que ponen en duda el propio sistema de representaciones sociales hegemónico. La utilización de esta clave metodológica posibilita poner el acento, en términos epistemológicos, en las dimensiones simbólico-culturales que permiten al mismo tiempo presenciar las modalidades en que lo social se vuelve visible, mediante la problematización de aquellas naturalizaciones y reificaciones que cotidianamente pasan desapercibidas ante nuestros ojos, así como analizar las reubicaciones de los lugares de enunciación en que se emplazan los distintos actores de un conflicto, expresando de esta manera nuevas relaciones de fuerza, usos diferenciados y diferentes de los discursos sociales que constituye un estratégico control de dichas codificaciones y matrices discursivas. Inicialmente señalamos que la unidad de análisis está conformada por las publicaciones periódicas para y desde el mundo juvenil que refieran a los siguientes acontecimientos: la constitución de la FECH en 1906, la candidatura presidencial de Huidobro en 1925, la masacre del seguro obrero en 1938, la revuelta de la chaucha en 1949, la toma de la población La Victoria en 1957, la toma de la casa central de la Universidad Católica en 1968, el festival de piedra roja en 1970, y el paro nacional del 2 y 3 de julio de 1986.

Estos acontecimientos se constituyen en las "puertas de entrada" a la época y los discursos sociales, y tuvieron la función de permitir recortes históricos y culturales que nos posibilitarán el trabajo empírico y acotado con los materiales.

\section{Procedimientos de análisis}

En este estudio, aquello que se dice en las publicaciones periódicas remite a un conjunto de prácticas sociales y cognitivas que pueden ser analizadas mediante el análisis del discurso y cuyo objetivo no es otro que articular procedimientos de análisis e interpretación sobre lo explícito y lo implícito en todo discurso social. Aquí se analizarán los atributos ideológicos y simbólicos asignados a la juventud a través de su simbología pictórica, el lenguaje utilizado, al tiempo que se estudia el papel de dichas atribuciones en los procesos de objetivación y anclaje dentro de la sociedad chilena. Además, dicha metodología nos permite adentrarnos en las condiciones mismas en que se han producido aquellos textos o, que es lo mismo decir, al proceso de producción social del discurso.

Inicialmente señalamos que desde la perspectiva de la construcción cultural de la juventud, y el papel que juegan las industrias culturales al proponer imágenes de ser joven, se utilizarán como categorías analíticas derivadas de la discusión teórica enunciada y que apuntan a los atributos culturales que recorren la constitución de lo juvenil: la construcción del cuerpo joven, los saberes que sustentan los discursos, el papel de los consumos materiales y simbólicos, y los usos y asignaciones sociales diferenciados respecto a los espacios institucionales y de sociabilidad reconocidos. El procedimiento de análisis discursivo, siguiendo a Foucault (1992:50), ha procedido a distinguir dos conjuntos operacionales: 
a) Conjunto crítico. En esta operación se pretende acceder al sistema de exclusión que funda el discurso (joven/adulto), la función de delimitación que apunta al conjunto de saberes y dispositivos en la base de la creación de la idea de juventud, y un reconocimiento a los modos de apropiación de estos discursos por parte de la sociedad. Este conjunto se traduce en el reconocimiento de las emergencias identitarias.

b) Conjunto genealógico. En un segundo nivel operativo, interesa interrogar cómo se han formado los discursos (continuidad, yuxtaposición, simultaneidad), con cuáles resultados de gobierno y que remiten a la especificidad de saber, y en qué contextos sociohistóricos se produjeron. Este conjunto genealógico se traduce en el reconocimiento de los regímenes de juvenilidad.

\begin{tabular}{|l|l|l|l|l|}
\hline & Cuerpo & Saberes & Consumos & Espacios \\
\hline Conjunto Crítico & & & & \\
Exclusión & & & \\
Delimitación & & & \\
Apropiación & & & \\
\hline Conjunto Genealógico & & & & \\
Discontinuidad & & & \\
Especificidad & & & \\
Exterioridad & & & & \\
\hline
\end{tabular}

Figura 1. Matriz de análisis

Esta metodología nos ha permitido una aproximación diacrónica a las diversas trayectorias que ha tenido la idea de juventud y su concreción en determinadas identidades reconocibles en el siglo XX. El trabajo de escritura se orientó entonces a reconocer el escenario de las revistas producidas para y por jóvenes, y las principales estrategias comunicacionales desplegadas, la reconstrucción de las diversas emergencias identitarias de lo juvenil existentes en la sociedad chilena de la época, así como en la identificación de los regímenes de juvenilidad que funcionan como matrices de discurso generadoras de verdad sobre el sujeto joven. Por tratarse de una investigación en desarrollo, se presentan resultados derivados del análisis del período 1900-1940.

\section{Resultados parciales}

\section{Estrategias comunicacionales}

Desde comienzos de 1900 se puede reconocer una importante presencia de magazines y publicaciones periódicas que aluden al sujeto joven. Dichas publicaciones fundamentalmente provienen de asociaciones juveniles y en mucha menor medida de la industria cultural y mediática existente.

Se trata de publicaciones en las que la palabra escrita predomina, y solo gracias a la introducción de tecnología de impresión a partir del año 1920 se incorpora progresivamente imágenes: fundamentalmente dibujos y posteriormente fotografías. 
No existe una editorialidad clara en estas primeras publicaciones, y más bien despliegan en sus páginas un conjunto heterogéneo de poesías, ensayos filosóficos y comentarios de actualidad, con un componente importante de informaciones sobre la vida social como fiestas, eventos sociales y actividades culturales.

En cuanto a la forma económica que sostiene estas experiencias de comunicación, la manutención de las revistas y magazines juveniles analizados evidencia en un primer momento una gestión basada en los "aportes voluntarios" de socios e interesados, acción más evidente en revistas adscritas a categorías asociativas y de colectivos juveniles, como también una gestión financiera proveniente de espacios institucionales como los partidos políticos y la iglesia. Sin embargo, la utilización de publicidad se introdujo poco a poco en las distintas revistas constituyéndose en una posible explicación del aumento y consolidación de las revistas mediáticas creadas por la industria cultural.

\section{a) El campo de las revistas juveniles en las primeras décadas}

La cantidad de revistas producidas en el siglo XX para la juventud y desde agrupaciones y colectivos juveniles tuvo un incremento considerable sobre todo en las primeras cuatro décadas. Hay un alza del 57,2 \% entre los años 1906 y 1924 por ejemplo, elevándose la cifra exponencialmente en un 81,9 \% a fines de la tercera década en comparación con el inicio del siglo. De esta forma, las revistas en su generalidad logran un aumento que luego se va estabilizando en el tiempo a partir de la tercera década.

El trabajo con material documental supone un conjunto de condicionamientos que es necesario reconocer, el principal de los cuales es el acceso al conjunto del material declarado y su disponibilidad para la comunidad investigativa. El trabajo de archivo en esta investigación no escapa a dichas constricciones: no fue posible acceder a todo el material declarado en las bases de datos de la Biblioteca Nacional fundamentalmente por la mala manutención de los documentos en archivo. Así un 26,9 \% de revistas catastradas estaban en condición de deterioro o extravío, según fue informado por los funcionarios de la Dirección de Bibliotecas, Archivos y Museos (DIBAM).

Por ello es que las revistas producidas para o desde el mundo juvenil a las cuales se pudo acceder y registrar -representan el 73,1 \% del universo total de revistas catastradasindican un incremento relativamente similar a los datos anteriores. Entre mediados de la primera década hasta fines de la tercera se observó un incremento de 70 \% de revistas, y un $83,6 \%$ de aumento en la cantidad de documentos dentro de estas publicaciones que remitían a ideas e imágenes sobre lo juvenil.

Esta alza es coincidente con el aumento en los índices de alfabetización de la población chilena: si a fines del siglo XIX un 68 \% de la población era analfabeta, la cifra desciende a un 50 \% para 1920 (Huidobro y Escobar 2012). De otra forma, aumenta el potencial público lector, y esto se debe fundamentalmente a la ampliación sostenida de la educación y particularmente a la expansión de la Educación Secundaria mediante la creación de liceos en diversas regiones del país. 
Esta alza en la producción de revistas también evidencia la diversificación de enunciadores: no solo diversas publicaciones sino fundamentalmente diversas organizaciones que emprenden iniciativas comunicacionales. A comienzos del siglo XX las revistas juveniles eran principalmente asociativas y la Editorial Zig-Zag representa a la única de carácter mediático o proveniente de una incipiente industria cultural nacional. Desde mediados de la segunda década se observó una explosión de producción de revistas de adscripciones religiosas, políticas, asociativas y mediáticas, con una mayor diversidad de los lugares de producción, como también una circulación nacional de dichas revistas y de producción en zonas alejadas al centro del país. Esta diversificación se mantiene a lo largo del tiempo, y solo tiene una baja desde la década de los setenta.

\section{b) Publicidad y consumo}

Por otra parte, uno de los elementos centrales que comenzó a aparecer en las revistas después de la segunda década principalmente, es el uso de publicidad y la idea de los jóvenes como actores de consumo. Las revistas presentan nuevas estructuras de organización de la información donde el espacio para la publicidad tuvo cada vez mayor realce, así como también la gestión editorial parece desplazarse y relegarse poco a poco al mercado en la mayoría de los casos.

El consumo progresivo de elementos no de primera necesidad, sino objetos y accesorios, tal como autos, productos de belleza, moda y cigarrillos -entre tantos otros- constituye una de las ideas a transmitir por parte de las revistas, y se transforma en elemento central en la década de los veinte y transversales después de la década de los treinta. Si bien desde muy temprano existe publicidad -remitida esencialmente a un mercado local- la globalidad de ciertos productos inunda las distintas revistas y emplaza a la juventud como sujeto activo de la relación económica; así, no solo se promociona a partir de una estrategia que articula a la idea juventud como deseo, sino de consolidación para los diferentes productos necesarios para la concreción de esa idea juvenil.

La utilización de imágenes publicitarias se volvió de uso frecuente y es uno de los elementos distintivos para observar las transformaciones en los modos comunicativos, así como para analizar el proceso por el cual los deseos mercantiles persuadieron a la juventud como agente de consumo. Se observa una direccionalidad que emplaza a la juventud a consumir productos internacionales, estableciendo "modas" y determinada figuración de su cuerpos, y que tiene como mecanismos de insistencia el uso de fotografías y dibujos idealizados sobre una presencia joven. Cabe destacar cómo los regímenes de visualidad operan dentro de las revistas y connotan las distinciones entre el mundo adulto a partir de signos visuales, y es este uno de los elementos que se perciben como necesarios de ahondar.

\section{Emergencias identitarias de lo juvenil}

Podemos sostener, en este nivel de desarrollo de nuestra investigación, que los signos e imágenes puestos en circulación en las múltiples revistas sistematizadas indican cambios que desestabilizan y estabilizan, según medio, adscripción y momento histórico, 
las identidades que se presentan. La pluralidad de jóvenes entonces es el resultado de una pluralidad de revistas analizadas.

Sin embargo, la figura masculina captura (contiene y excluye) la representación de lo juvenil en cuanto a revistas asociativas provenientes del mundo juvenil donde las mujeres jóvenes solo aparecen como objeto de contemplación y musas inspiradoras para los varones jóvenes. Algo similar ocurre en las revistas provenientes de partidos políticos.

Por el contrario, en las revistas provenientes de la industria de la cultura las mujeres jóvenes o señoritas tienen una centralidad importante en sus referencias editoriales, de crónicas y fundamentalmente en cuanto a los productos de consumo.

Las revistas de origen religioso, por su parte, presentan mayores matices en cuanto a los sujetos juveniles hegemónicos en tanto lo que preocupa a estas publicaciones son fundamentalmente los valores sociales que se encuentran tensionados en la sociedad.

a) Jóvenes, el cuerpo masculino y hegemónico de la representación mediática

La construcción juvenil tiene como sujeto ideal al hombre, y los signos que marcan este cuerpo poseen características heterosexuales, lo ubican en los espacios públicos y en muchas ocasiones visibilizan al joven de elite. Así, las distinciones de clase solo serán visibles en discursos doctrinarios haciendo referencias a una juventud proletaria "allá fuera", pero es el joven ilustrado el que escribe y problematiza el acontecer durante la mayor parte del siglo.

En las primeras dos décadas del siglo el joven es un sujeto reconocido como actor social. Publicaciones como "La Universidad" (1906), por ejemplo, muestran a un joven interesado en hacer públicos los pensamientos y la cultura patriarcal de la época. La poesía es una de las estrategias comunicativas más recurrentes y visibles en las primeras dos décadas como mecanismo de realce de los atributos del joven. Se rescata también lo frecuente de la aparición del joven en revistas y boletines políticos; es en el joven donde se estructura y despliega la actoría y participación activa en la sociedad; sea de carácter formal o informal, se lo llama frecuentemente a ingresar a las filas de la militancia y la revolución.

\section{La emergencia femenina y juvenil}

El trabajo de archivo y análisis preliminar entregó un dato que deja en evidencia el cambio y centralidad que va adoptando la figura de la joven como destinataria principal de una mayoría de publicaciones para este grupo. Con ello, se abre una ruta de exploración que permita revertir el androcentrismo presente en los estudios de juventud (McRobbie 2010, Elizalde 2011)

Las publicaciones dirigidas a la juventud femenina muestran una cierta transformación en las primeras dos décadas del siglo. En un primer momento se observó, por un lado, un discurso que era dirigido a la experiencia de la "mujer", sin una clara distinción etaria para hablar sobre el sujeto en cuestión, lo que además con el tiempo fue incrementando 
en cantidad de artículos sobre su experiencia en los ámbitos privados y algunos públicos como el derecho a la educación. Por otro lado, la aparición de "las señoritas", construcción discursiva primaria para la denominación de la joven, comenzó a aparecer como central en documentos y revistas asociativas.

En un segundo momento, articulado principalmente desde mediado de los años veinte en adelante, la joven aparece como un sujeto que culturalmente está en vías de definición. La idea de las "señoritas" se va consolidando en la medida que sus actividades e imágenes son más recurrentes en la prensa. La joven como sujeto se vincula idealmente con el mundo del goce, los deseos y la entretención - llama la atención la cantidad de documentos referidos a "Fiestas de la Primavera" y Concursos de belleza- en revistas como "Las Noticias" (1924) o "La Primavera" (1924).

Desde los años treinta se observa ya una consolidación de esta construcción etaria femenina entendida como "la joven", y es interesante reconocer que es uno de los destinatarios principales de la industria de la cultura, donde una serie de revistas como "La Vichuca" (1937) o "Margarita" (1935) son ejemplos extraordinarios de cómo las revistas giran en torno a ofrecer pautas de comportamiento socialmente adecuado para la joven.

Este tipo de publicaciones tiene un crecimiento exponencial en las siguientes décadas, con un cambio de énfasis en la información a transmitir a la joven. Podemos decir que en un primer momento los discursos son principalmente normativos y edificantes, y aunque posteriormente no hay una disminución de estos elementos, ya que los discursos sobre el cuerpo, la moral y la sexualidad se exponen más abiertamente pero con una clara intención moralizante y patriarcal, sí aparecen nuevos tópicos que visibilizan a la juventud femenina en los espacios públicos -consumiendo, paseando-, y sobre todo como el sujeto ideal para referir las prácticas de consumo que serán evidentes sobre todo en la publicidad.

\section{Otras juventudes}

La otredad puede definirse como aquellas identidades que existen por fuera de los cánones hegemónicos de representación sexual, étnica y socioeconómica. Se han indicado con anterioridad los mecanismos de emergencia de la juventud proletaria y es posible reconocer que quedan en una posición de exclusión.

Los lugares de dominio donde es puesta la información a circular es realizada por los hombres -e incluso algunas mujeres-ilustrados y pertenecientes a la elite. Así, son jóvenes con capitales culturales y económicos quienes tienen los medios de producir y hacer circular información, como también determinadas representaciones y discursos sobre el bienestar. Los jóvenes en condición de pobreza son solo reconocidos y puestos en circulación como otredad noticiosa e inquietud de los partidos, por ejemplo, pero sin ser ellos los que enuncian y definen las características específicas de una juventud proletaria.

Por otro lado, la invisibilidad de la presencia indígena deja en evidencia la exclusión de la etnia como marcador en la construcción de lo juvenil. Culturalmente la juventud se despliega sobre cuerpos blancos, y es notorio cómo en gran parte del siglo las represen- 
taciones de hombres y mujeres jóvenes se inscriben en este estereotipo. La blancura no es tan solo el lugar de comienzo, sino que en la medida que las representaciones muestran a más sujetos oscuros, comienza a parecer un ideal de ser. Es la publicidad en ese sentido una de las estrategias comunicacionales con mayor sesgo colonial, sin embargo no la única, ya que las múltiples imágenes solo retratan este tipo de corporalidades.

Así, también, la presencia de "juventud rural" es igualmente invisibilizada. Parece ser que esta identificación no se cruza con los ideales culturales que permitieron la construcción del sujeto juvenil. Ello se aprecia incluso en las propias producciones de jóvenes que residen fuera de las grandes urbes en donde el deseo por lo urbano define a una determinada juventud.

\section{Sobre regímenes de juvenilidad}

En un ordenamiento preliminar, se reconocen cuatro regímenes de juvenilidad en las publicaciones periódicas chilenas:

a) Actoría. La actoría juvenil tiene características que no remiten solo a las ideas del joven militante en un partido político específico, sino de una manera amplia que permite decir que se trata de un actor social involucrado en el acontecer nacional y despliega estrategias comunicacionales para levantar la voz y reconocer el trabajo de los pares y sus dificultades. La actoría como régimen es totalizante en las primeras dos décadas del siglo.

b) Juventud como déficit. El segundo régimen de juvenilidad reconocido remite a la idea de la juventud vista en déficit. Desde los años treinta en adelante la juventud se vincula a la idea de "adolescencia", término que ha logrado globalmente una acumulación de saberes vinculados principalmente a la psicología y ubica las acciones de los individuos en el marco de paradigmas médicos y evolucionistas. La representación juvenil pasa drásticamente de un joven como actor social y sujeto en vías de validación ciudadana, a una en que lo reconoce como grosero, inestable y en proceso de cambios. La edad aparece "atada al cuerpo", y el saber médico define etapas por la que se debe transcurrir para llegar a una adultez adecuada, por lo que los discursos de "expertos" en estas áreas, así como aquellos de los padres o adultos modelos, forman parte de lo que es puesto en circulación a modo de "explicación" de la conducta.

c) Un tercer régimen juvenil comienza a aparecer desde la década del cincuenta y se perfila como "el Joven-problema". Los discursos sobre el cuerpo, la sexualidad, el consumo de drogas y la delincuencia son los tópicos en que la presencia juvenil es un problema. El joven es reconocido ya como un sujeto inestable a partir de las ideas psicologistas que han ido definiendo su accionar; por lo mismo, "el peligro" de determinadas acciones es una de las ideas más recurrentes en la prensa. Las drogas, las protestas y la delincuencia forman parte de lo puesto en circulación que indica a los jóvenes como los actores que más recurren en estas "faltas" y un discurso sobre "los cambios en la juventud" comienza a surgir como modo explicativo para el cambio de régimen. 
El corte moralizante en que las temáticas sobre el cuerpo y la sexualidad son tratadas recorre transversalmente las publicaciones. Las revistas religiosas hablan de sexualidad y pecados, y las revistas comerciales sitúan a expertos para articular discursos sobre lo no permitido.

d) Un cuarto régimen reconocido lo denominamos jóvenes como mercancía y es visible desde los años treinta como la génesis de una construcción de visibilidad de la juventud y que aumenta pausada pero firmemente en todo lo que va del siglo. Los jóvenes son los actores y cuerpos donde se despliegan las ideas sobre lo deseable, y son los consumidores más activos. Esto se incrementa en la medida que la industria cultural va desarrollándose y fijando a la juventud como modelo.

Los ídolos son una de las expresiones en que este régimen es visible. Las publicaciones después de los años cuarenta y desde distintas adscripciones señalan en ellos los atributos y fijaciones adecuados a los modos de ser de la juventud.

\section{Conclusión}

La existencia social de la juventud en Chile ilumina no solo a este grupo social específico, sino que pone en escena el propio proceso de modernización que se experimentó en las primeras décadas del siglo XX. La visibilidad pública y su reconocimiento identitario serían, por tanto, uno de los aspectos que permiten comprender la emergencia de un actor social claramente diferenciado a partir de los primeros años del siglo XX. Esta delimitación temporal de la juventud es coherente con su estabilización semiótica en los discursos públicos existentes en la sociedad chilena. No se trata de que en el siglo XIX no se hable de juventud, sino que los atributos culturales que hoy le asignamos se estabilizaron en las primeras décadas del siglo XX y, por tanto, permiten asegurar grados de comparabilidad sociocultural y que aporten a la discusión sobre la "fecha de nacimiento de la juventud".

El proceso antes descrito va conformando una idea de juventud que ya en 1925 es reconocida públicamente; sus atributos culturales son incorporados como marca identificatoria para aquellos sujetos que se nombrarán en adelante como la juventud chilena y quedan retratados en palabras del poeta Huidobro:

Nuestro gesto es solo un gesto de afirmación magnifica. Existimos y queremos probarlo. En medio de la baba gaseosa que se respira en el ambiente chileno, en medio de la piara estúpida y taciturna que enmienda de mediocridad nuestra vida cotidiana, hemos lanzado un grito y es preciso que este grito, reflejo de todos nuestros anhelos, se condense en el espacio como la nebulosa que forma un sol de primera magnitud (...) iHicimos nacer la juventud!

Desde esa perspectiva, sin lugar a dudas, la pregunta por la juventud pone en escena las propias tensiones, cambios y continuidades por los que atraviesa la sociedad en su conjunto, y nos permiten ratificar la comprensión de ella como metáfora de lo social. Es decir, que en su propia existencia social encontramos condensados el conjunto de procesos por los que atraviesa una comunidad mayor. 
Así entendemos la apropiación y homologación inicial entre juventud y varones, que viven en la ciudad y forman parte de la clase media alta, lo que de alguna manera imprime un sello particular que tendrá como consecuencia inmediata la invisibilización de "otras juventudes" principalmente la femenina, la de sectores populares y aquella que por residencia vive en fuera de las ciudades. Sin duda que esta mayor visibilidad habría que entenderla a partir de su inscripción en los regímenes de juvenilidad que han sido identificados.

Por otra parte, destacamos la temprana relevancia que adquiere el dispositivo del consumo y la publicidad en el proceso que va produciendo juventud. Focalizar en este "lugar" que no solo produce significados (atributos) sino el propio "deseo de ser" joven es una de las rutas de profundización de este proceso investigativo, en tanto ese imaginario de consumo produjo inicialmente el deseo de juventud como precedente a la llegada/ existencia misma de la juventud en lo que algunos teóricos denominan contemporáneamente como neopolitica (Lazzarato, 2006).

\section{Bibliografía}

Aguilera, O. (2009). Estudios sobre juventud en Chile. Coordenadas para un estado del arte. En Revista Última Década, Diciembre 2009.

Angenot, M. (2010). El discurso social; los limites históricos de lo pensable y lo decible. Buenos Aires: Editorial Siglo Veintiuno.

Barbero, J. (2002). Jóvenes: comunicación e identidad. Recuperado el 10/05/2012 en: www.comisionporlamemoria.org/investigacionyense\%C3\%Blanza/pdf _ biblioteca/Barbero.pdf

Bernedo, P. (2004). Balance de la historiografía de las comunicaciones en Chile. Comunicação E Sociedade. São Bernardo do Campo: PósCom-Umesp, n. 41, p. 153-170, (primer semestre), 2004.

Castro- Gómez, S. (2009). Tejidos oníricos: Movilidad, capitalismo y biopolítica en Bogotá (1910-1930). Editorial Pensar, Colombia.

Chaves, M. (2006). Informe de investigación sobre el estado del arte en estudios sobre juventud en Argentina. Sin Editar.

De Certeau, M. (1995). La toma de la palabra y otros escritos políticos. México D. F.: Universidad Iberoamericana.

De Marinis, P. (1999). Gobierno, gubernamentalidad Foucault y los anglofoucultianos (o un ensayo sobre la racionalidad política del neoliberalismo). En García y Ramos Torre (comps.), Globalización, riesgo,reflexividad. Tres temas de la teoría social contemporánea. Madrid: Centro d e Investigaciones Sociológicas

Durham, D. (2000). Anthropological Quarterly, Volume 73, Number 3, July 2000, pp. 113 120.

Escobar, M. (2004). Estado del Arte de la producción de conocimiento sobre juventud en Colombia. Sin editar, IESCO-GTZ.

Feixa, C. (2008.) De jóvenes, bandas y tribus. Barcelona: Editorial Ariel.

Foucault, M (2008). Nietzsche, la genealogía, la historia. Pre-Textos, Valencia. 
González, Y. (2010) Primeras culturas juveniles en Chile: Pánico, malones, pololeo y matiné. Atenea (Concepc.) [online]. 2011, n. ${ }^{\circ}$ 503, pp. 11-38.

Gramsci, A. (1975). EL materialismo histórico y la filosofía de Benedetto. Croce, Juan Pablos, Editor, México 1975

Hall, S. G. (1915). Adolescence: Its Psychology and its relations to Psysiology, Sociology, Sex, Crime, Religion and Education. Appleton Century Crofts. New York.

Huidobro,C; Escobar, P. (2012). Una historia de las revistas chilenas. Ediciones Universidad Diego Portales, Santiago

Hurtado, M. (1989). Historia de la tv en Chile (1958-1973). Ediciones Documentas, Santiago:

Lazzarato, M (2006). El pluralismo semiótico y el nuevo gobierno de los signos. Homenaje a FelixGuattari. Consultado en: http://eipcp.net/transversal/0107/lazzarato/es

McRobbie, A: Gerber, J. (2010). Chicas y subculturas: una exploración. En Hall,S y Jefferson,T (eds). Resistencia a través de rituales. Subculturas juveniles en la Gran Bretaña de posguerra. Editorial Observatorio de Jóvenes Comunicación y Medios, La Plata.

Manheim, K. (1993). El problema de las generaciones. En Reis: Revista española de investigaciones sociológicas $N^{\circ}$ 62, Madrid.

Mattelart, A; Mattelart, M. (1970). La juventud chilena: rebeldía y conformismo. Santiago: Editorial Universitaria.

Mead, M. (1985). Adolescencia, sexo y cultura en Samoa. Editorial Planeta. Barcelona.

Morch, S. (1996). Sobre el desarrollo y los problemas de la juventud. El surgimiento de la juventud como concepción sociohistórica. En Jóvenes, Revista de Estudios sobre Juventud, SEP-Causa Joven/CIEJ, año 1, núm.1, julio-septiembre de 1996, México. Pp 78-106.

Muñoz, G. (2006). La comunicación en los mundos de vida juveniles : hacia una ciudadanía comunicativa. Tesis Doctoral en Ciencias Sociales, Universidad de Manizales, Manizales.

Musgrove, F. (1965). Youth and the social order. Blomington, Indiana UniversityPress.

Ortega y Gasset, J. (1955). El tema de nuestro tiempo. Espasa-Calpe, octava edición. Madrid.

Pérez-Islas, J. y Urteaga, M. (2004). Historias de los jóvenes en México. Su presencia en el siglo XX SEP, IMJ, 2004.

Ossa, C. (1999). La pantalla delirante. Los escenarios de la comunicación en el Chile de Hoy. Editorial LOM.

Ossandón, C. (2002). Los inicios de la «cultura de masas» en Chile. En Historia y Comunicación Social Vol. 7 (2002) 161-167

Ossandón,C; Santa Cruz, E. (2001). Entre las alas y el plomo. Editorial LOM. Santiago

Reguillo, R. (2000). Estrategias del Desencanto. Emergencia de Culturas Juveniles. Editorial Norma, Enciclopedia Latinoamericana de Sociocultura y Comunicación. México.

Rodrigo Alsina, M. (1999). La comunicación intercultural. Barcelona: Anthropos.

Rojas, J. (2009). Historia de la infancia en el Chile Republicano 1810-2010. JUNJI.

Salazar, G. y Pinto, J (2002). Historia de Chile V.5. Infancia y Juventud. LOM Ediciones. 
Santa Cruz, E. (1999). Conformación de espacios públicos masificación y surgimiento de la prensa moderna en chile Siglo XIX. Cuadernos de Trabajo, Universidad ARCIS.

Savage, J. (2009). A criacão da Juventude. Como o conceito de teenagerevolucionou o século XX. Río de Janeiro: Rocco.

Toro, P (2012). Dimensiones de la confección de una juventud virtuosa: manuales de urbanidad en Chile (c.1840-c.1900). UNIVERSUM No 27, Vol. 1, Universidad de Talca

Touraine, A. (1997). Juventud y Democracia en Chile. En Revista Última Década No 8. Ediciones Cidpa. Viña del Mar, Chile.

Urteaga, M. (2004). Imágenes juveniles del México moderno. En Pérez-Islas, J y Urteaga, M. (2004) Historias de los jóvenes en México. Su presencia en el siglo XX SEP, IMJ, 2004.

Valles, M. (1999). Técnicas cualitativas de investigación social. Reflexión metodológica y práctica profesional. Editorial Síntesis, Madrid.

Vasconcelos, J. (1966). La raza cósmica: misión de la raza iberoamericana. Espasa-Calpe México

Whyte, W. F. (1971). La sociedad de las esquinas. México, Diana. 